\title{
Measurement of the Mass Specific Extinction Coefficient of Acetylene, Toluene and Polymethyl Methacrylate Soot Particles In Visible and Near-Infrared Wavelengths
}

\author{
FRANÇOIS-XAVIER OUF ${ }^{1}$, ALEXIS COPPALLE $^{2}$, JEROME YON ${ }^{2}$ and JACQUES VENDEI ${ }^{1}$ \\ 1 Institut de Radioprotection et de Sûreté Nucléaire, Laboratoire de Physique et Métrologie des \\ Aérosols, BP 68, 91192 Gif-sur-Yvette Cedex, France \\ 2 UMR 6614, CORIA, Université de Rouen, Avenue de l'université, BP 8, \\ 76801 Saint-Etienne du Rouvray, France
}

\begin{abstract}
An experimental set-up has been developed to determine the mass specific $\sigma_{\mathrm{s}}$ and the dimensionless extinction $\mathrm{K}_{t}$ coefficients of soot particles at visible $(632 \mathrm{~nm})$ and near-infrared $(1064 \mathrm{~nm})$ wavelengths. Near-infrared measurements have been carried out with a multiple-path extinction cell to increase the measurement accuracy. The extinction coefficient $\mathrm{K}_{\text {ext }}$ has been analysed as a function of the mass concentration, measured by a Tapered Element Oscillating Microbalance (TEOM 1105 R\&P) in order to retrieve the soot mass specific extinction coefficient, $\sigma_{\mathrm{e}}$, in the smoke plume of acetylene, toluene and PolyMethyl MethAcrylate (PMMA) burning under turbulent, well-ventilated and small-scale conditions. Results for mass specific extinction coefficient $\sigma_{\mathrm{e}}$ are consistent with previous measurements (Mulholland \& Croarkin [1] and Newman \& Steciak [2]) obtained for a variety of fuels for small-scale fires. The mobility diameter distribution of the soot particles is measured using a Scanning Mobility Particle Sizer (SMPS 3936 TSI). The soot aggregate morphology is determined from Transmission Electronic Microscopy picture analysis. From these measurements, the soot volume fraction is determined and so the dimensionless extinction coefficient. Values at 632 and $1064 \mathrm{~nm}$ are given and discussed in comparison to other published data. It is found the scattering contribution to the extinction process is important for the present experimental conditions. For this reason, the use of the dimensionless coefficient is expected to provide a more accurate soot volume fraction value than the calculation which assumes the scattering is negligible.
\end{abstract}

KEYWORDS: smoke, mass specific extinction coefficient, soot optical properties, soot volume fraction

\section{NOMENCLATURE LISTING}

\begin{tabular}{|c|c|c|c|}
\hline $\begin{array}{l}d p p \\
\mathrm{D}_{\mathrm{g}}\end{array}$ & $\begin{array}{l}\text { spherule (primary particle) } \\
\text { diameter } \\
\text { gyration radius of an aggregate }\end{array}$ & $\begin{array}{l}D f \\
T_{o}\end{array}$ & $\begin{array}{l}\text { aggregate fractal dimension } \\
\text { ambient temperature }(\mathrm{K})\end{array}$ \\
\hline $\mathrm{D}_{\mathrm{mb}}$ & aggregate mobility diameter & $m$ & refractive index of soot \\
\hline $\begin{array}{l}E(m), F(m) \\
F(D)\end{array}$ & $\begin{array}{l}\text { refractive index functions } \\
\text { diameter distribution }\end{array}$ & $\begin{array}{l}N \mathrm{p} \\
\text { Greek }\end{array}$ & number of spherules per unit volume \\
\hline$f v$ & Soot volume fraction & $\lambda$ & wavelength of light \\
\hline$k f$ & fractal prefactor & $\sigma_{\mathrm{e}}$ & specific extinction coefficient \\
\hline Kabt & Absorption coefficient & $\rho_{\mathrm{s}}$ & soot particle density \\
\hline $\begin{array}{l}K_{\text {sca }} \\
K_{\text {ext }}\end{array}$ & $\begin{array}{l}\text { scattering coefficient } \\
\text { extinction coefficient } \\
\text { dimensionless extinction }\end{array}$ & $\beta$ & $\mathrm{D}_{\mathrm{g}} / \mathrm{D}_{\mathrm{mb}}$ \\
\hline $\mathrm{Ke}$ & coefficient & & \\
\hline
\end{tabular}

\section{INTRODUCTION}

The determination of soot volume fraction in flame or post-flame zones of fires is a major problem and accurate soot optical properties are needed for correct interpretation of laser-based determination of soot 
volume fraction. If light extinction is considered, the mass specific extinction coefficient $\sigma_{e}$ is used to retrieve concentrations using the Bouguer's Law, which links the ratio of initial $\mathrm{I}_{0}$ to extinguished I signal to the mass concentration of soot $\mathrm{C}_{\mathrm{s}}$ and the optical path $\mathrm{L}$ :

$$
\frac{I}{I_{0}}=\exp \left(-K_{e x t .} .\right)=\exp \left(-\sigma_{e} . C_{s .} . L\right)
$$

One can also define Ke the dimensionless soot extinction coefficient,

$$
\frac{I}{I_{0}}=\exp \left(-K_{e x t} \cdot L\right)=\exp \left(-K_{e} \cdot f_{v} . L / \lambda\right)
$$

where $f_{v}$ is the soot volume fraction and $\lambda$ the wavelength. Many researches have been carried out in order to determine the mass specific extinction coefficient or the dimensionless soot extinction coefficient for a large number of fuels. Mulholland and Croarkin [1], Newman and Steciak [2] and recently Xhu [3,4] have reported a consequent number of experimental results obtained in the visible and infra-red wavelengths range for several types of fuels. The present study is similar to these previous works for the determination of the extinction coefficient Kext but integrates a mass concentration measured by a Tapered Element Oscillating Microbalance in order to retrieve the soot mass specific extinction coefficient and the mobility diameter distribution of soot particles in order to retrieve the size of these aggregates. Consequently the present work introduces the usefulness of size distribution of soot particles in the estimation of their volume fraction. The experimental set up and soot production facility are presented. $\sigma_{\mathrm{e}}$ and $\mathrm{K}_{\mathrm{e}}$ results at 632 and $1064 \mathrm{~nm}$ are given and discussed.

\section{EXPERIMENTAL METHOD}

\section{Experimental conditions and soot production facility}

Experiments were performed in the facility presented in Fig. 1. More details on the experimental method can be found in the reference of Ouf et al [5], however it is briefly described below.

The fire zone is located in a furnace of approximately $1 \mathrm{~m}^{3}$ surmounted by a hood connected to a $114 \mathrm{~mm}$ diameter vertical ventilation duct. Depending on fuel and ventilation system, the global equivalence ratio (GER) lies in the fuel-lean regime, ranging from $10^{-2}$ to almost 1 and is controlled by airflow rate monitoring. In this study, the GER is defined as the ratio between the mass ratio of air to fuel and mass ratio of air to fuel at stoichiometry. Three different fuels have been used: acetylene (gas), toluene (liquid) and solid polymer, PolyMethyl Methacrylate (PMMA). The burner associated with acetylene is similar to the one used in previous studies by Köylü and Faeth [6]. Liquid (toluene) and solid (PMMA) fuels are respectively burnt in a cylindrical vessel of $15 \mathrm{~cm}$ diameter x $30 \mathrm{~cm}$ height and a $30 \mathrm{~cm}^{2}$ x $15 \mathrm{~cm}$ rectangular recipient. The flames for all fuels are strongly turbulent and experimental conditions are detailed in table 1 . Soot particles are sampled in the ventilation duct with a two-stages dilution device (DEKATI FPS 4000) and particles exiting the dilution device are at ambient temperature and pressure conditions.

Mass concentration $\mathrm{C}_{\mathrm{s}}$ of soot particles is measured with a Tapered Element Oscillating Microbalance (TEOM R\&P 1105). The mobility diameter distribution of soot aggregates is retrieved with a Scanning Mobility Particle Sizer (SMPS TSI 3936). The soot particles are sampled on a nuclepore filter of $0.8 \mu \mathrm{m}$ pore diameter at the output of the dilution device and post-treatment is applied on these filters. The filters are dissolute in a chloroforme flux and during this dissolution, the sample is deposed on TEM grid. The morphological parameters (fractal dimension $\mathrm{D}_{\mathrm{f}}$, fractal prefactor $\mathrm{k}_{\mathrm{f}}$ and primary particle diameter $\mathrm{D}_{\mathrm{pp}}$ ) of soot particles are determined by analysis of TEM micrographs (about 50 for each fuel ), using the method introduced by Köylü et al. [7] and Sorensen and Feke [8]. 
Table 1. Experimental conditions and turbulent diffusion flames properties

\begin{tabular}{|c|c|c|c|c|}
\hline Fuel & $\begin{array}{c}\text { Diameter } \\
\text { of Burner } \\
\text { (mm) }\end{array}$ & $\begin{array}{c}\text { Heat } \\
\text { Release } \\
\text { Rate (kW) }\end{array}$ & $\begin{array}{c}\text { Ventilation } \\
\text { Flow Rate } \\
\left(\mathbf{m}^{\mathbf{3}} / \mathbf{h}\right)\end{array}$ & \begin{tabular}{|c|} 
Global \\
Equivalence \\
Ratio $\phi$
\end{tabular} \\
\hline \multirow{2}{*}{$\begin{array}{c}\text { Acetylene } \\
\left(\mathrm{C}_{2} \mathrm{H}_{2}\right)\end{array}$} & \multirow{2}{*}{50} & \multirow{2}{*}{5.6} & 460 & 0.009 \\
\hline & & & 110 & 0.036 \\
\hline \multirow{2}{*}{$\begin{array}{l}\text { Toluene } \\
\left(\mathrm{C}_{7} \mathrm{H}_{2}\right)\end{array}$} & \multirow{2}{*}{150} & \multirow[b]{2}{*}{6.7} & 460 & 0.013 \\
\hline & & & 120 & 0.052 \\
\hline \multirow{2}{*}{$\begin{array}{c}P M M A \\
\left(\mathrm{C}_{5} \mathrm{H}_{8} \mathrm{O}_{2}\right)\end{array}$} & \multirow{2}{*}{340} & \multirow{2}{*}{26} & 530 & 0.063 \\
\hline & & & 170 & 0.23 \\
\hline
\end{tabular}

\section{Extinction measurements of soot particles}

The experimental device used for the determination of extinction coefficient is also shown in Fig. 1.

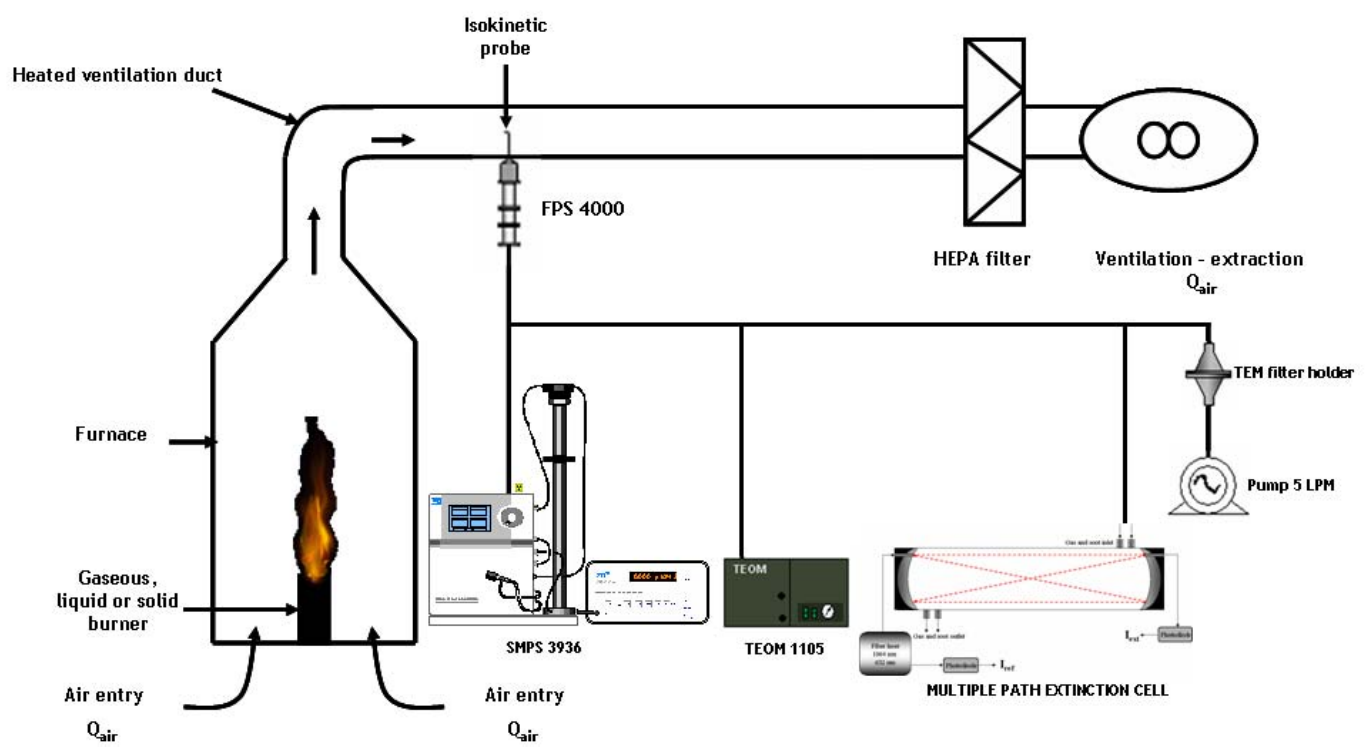

Fig. 1. Soot particles production and sampling . Set-up used for the determination of soot particles optical properties

Two diode-lasers of $1 \mathrm{~W}$ at $1064 \mathrm{~nm}$ and $30 \mathrm{~mW}$ at $632 \mathrm{~nm}$ were used to measure the optical properties of soot particles. The extinction cell is a multiple paths optical cavity composed of two hemispheric mirrors. This device allows us to extend, with a cell of only $1 \mathrm{~m}$ length, the optical path to several meters. The extinction signal is measured with a photodiode at the cell outlet, firstly the extinguished signal I for soot particles and secondly the initial signal $\mathrm{I}_{0}$ for filtered air. Comparison of these two signals with Bouguer's law (relation (1)) provides us the extinction coefficient.

\section{RESULTS AND DISCUSSIONS}

\section{Morphology and Size distributions and of soot particles}

Soot particles are fractal-like agglomerates. Figure 2 presents a TEM micrograph for acetylene. For All experimental conditions and the three fuels used in this work, the agglomerate soot particle TEM pictures are similar to the one shown in Fig.2. Soot particle aggregates observed in the present work are also very similar to the ones already shown in other studies [7-8]. 


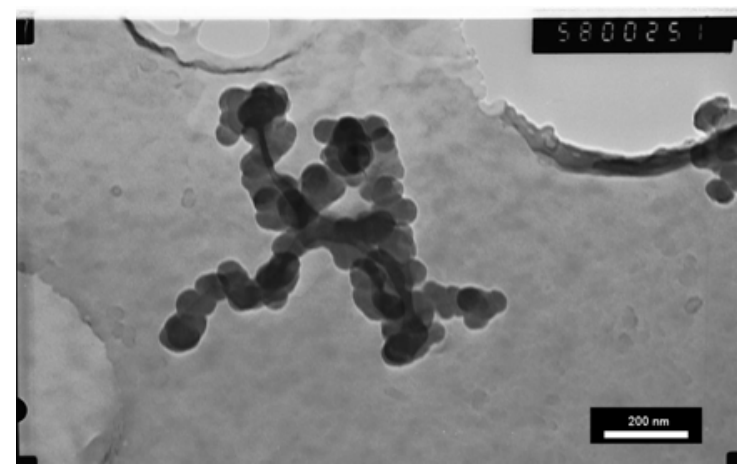

Fig. 2. Example of TEM micrograph of soot particle produced in the combustion chamber (acetylene case)

The soot particle morphology is described by two diameters: the primary particle diameter $\mathrm{D}_{\mathrm{pp}}$ and the gyration diameter $\mathrm{D}_{\mathrm{g}}$. The number of primary particle in each agglomerate is given by

$$
N_{p}=k_{f}\left(\frac{D_{g}}{D_{p p}}\right)^{D_{f}}
$$

where $\mathrm{D}_{\mathrm{f}}$ and $\mathrm{k}_{\mathrm{f}}$ are the fractal dimension and the prefactor. $\mathrm{D}_{\mathrm{f}}, \mathrm{k}_{\mathrm{f}}$ and $\mathrm{D}_{\mathrm{pp}}$ have been determined from TEM picture analyses. The average values of $\mathrm{D}_{\mathrm{f}}, \mathrm{k}_{\mathrm{f}}$ and $\mathrm{D}_{\mathrm{pp}}$ are given in table 2 for both ventilation rates. The fractal dimension $\mathrm{D}_{\mathrm{f}}$ and fractal prefactor $\mathrm{k}_{\mathrm{f}}$ are not particularly sensitive to GER values but on the other hand the primary particle diameter $D_{p p}$ increases significantly with equivalence ratio for toluene and PMMA. The density of the soot monomer has been measured using a standardized method (NF EN ISO 787-23) as described by Ouf [5]. The soot emission factors $\varepsilon$ of these flames are also detailed in this table and are in agreement with values reported by Köylü \& Faeth [9] and Tewarson [10].

Table 2. median value of mobility diameter distribution and morphological properties of soot particles

\begin{tabular}{|c|c|c|c|c|c|c|c|}
\hline Fuel & GER $\phi$ & $\begin{array}{c}\mathbf{D}_{\mathrm{m}} \\
(\mathrm{nm})\end{array}$ & $\begin{array}{c}\mathrm{D}_{\mathrm{pp}} \\
(\mathrm{nm})\end{array}$ & $\mathbf{D}_{\mathrm{f}}$ & $\mathbf{k}_{\mathrm{f}}$ & $\begin{array}{c}\varepsilon= \\
\mathbf{m}_{\text {soot }} / \mathbf{m}_{\text {tuel }}\end{array}$ & $\rho_{\mathrm{Dp}}\left(\mathrm{g} / \mathrm{cm}^{3}\right)$ \\
\hline \multirow{2}{*}{ Acetylene } & 0.009 & 233 & 66 & 1.85 & 2.31 & 0.23 & \multirow{2}{*}{1.72} \\
\hline & 0.036 & 233 & 64 & 1.93 & 1.68 & 0.18 & \\
\hline \multirow{2}{*}{ Toluene } & 0.013 & 184 & 52 & 1.86 & 1.89 & 0.19 & \multirow{2}{*}{1.50} \\
\hline & 0.052 & 222 & 61 & 1.81 & 2.62 & 0.14 & \\
\hline \multirow{2}{*}{$P M M A$} & 0.063 & 165 & 42 & 1.78 & 2.84 & 0.015 & \multirow{2}{*}{1.50} \\
\hline & 0.23 & 201 & 53 & 1.72 & 2.97 & 0.030 & \\
\hline
\end{tabular}

Figure 3 shows examples (acetylene case) of mobility diameter distributions observed with the SMPS for the two dilution ratios in the combustion chamber. Diameters of soot particles range from 50 to $2000 \mathrm{~nm}$, they are close to lognormal distributions and the median diameter $\mathrm{D}_{\mathrm{m}}$ tends to increase with increasing equivalence ratio as shown in table 2 . The gyration diameter $\mathrm{Dg}$ is deduced from the mobility diameter $D_{m b}$. The ratio $\beta$ between $D_{g}$ and $D_{m b}$ has been introduced by Rogak \& Flagan [11]. In the present work, we used $\beta$ constant value equal to 1.5. So the distributions $f\left(D_{g}\right)$ are deduced from the distributions $f\left(D_{m b}\right)$. 


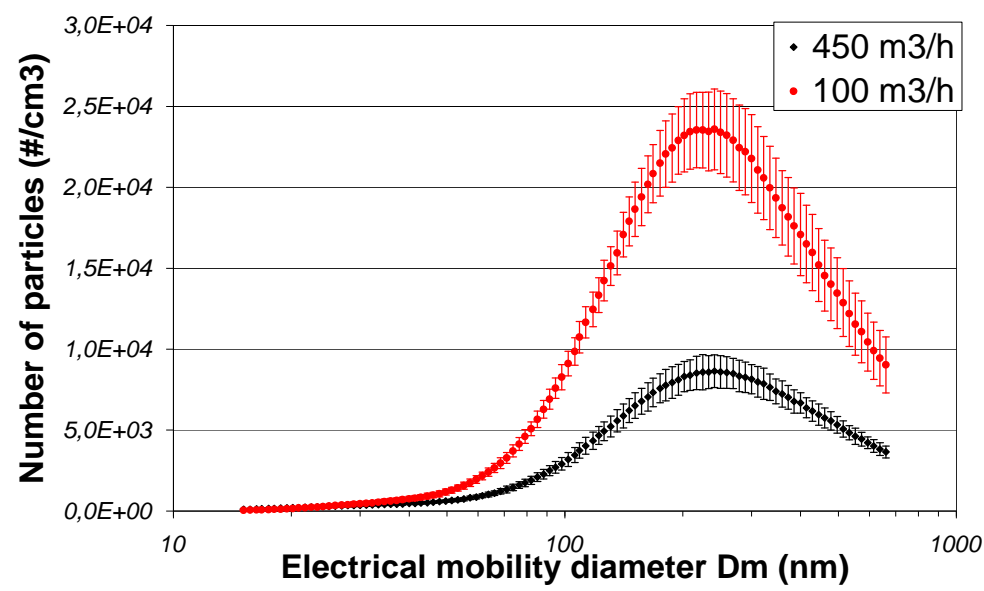

Fig. 3. mobility diameter distribution $\mathrm{f}\left(\mathrm{D}_{\mathrm{mb}}\right)$ at the two dilution ratios (acetylene case). Upper curve for $100 \mathrm{~m} 3 / \mathrm{h}$, lower for $450 \mathrm{~m} 3 / \mathrm{h}$

With the results obtained with the experimental set-up presented above, the mass specific extinction coefficient $\sigma_{\mathrm{e}}$, the soot volume fraction $\mathrm{f}_{\mathrm{v}}$ and dimensionless soot extinction constant $\mathrm{K}_{\mathrm{e}}$ are determined.

\section{Measurement of mass specific extinction coefficient}

The comparison between extinction coefficients and mass concentrations of soot particles is presented in Fig. 4. Results for all fuels have been presented separately on this figure but the linear regression has been applied by considering the whole set of experimental data. The main conclusion is that the mass specific extinction coefficient $\sigma_{\mathrm{e}}$ is not sensitive to fuel type at both wavelengths. Influence of fuel type is not significantly higher than the uncertainty of the method and no influence of ventilation flow rates is observed. This is in agreement with the work of Mulholland \& Croarkin [1] who have found that $\sigma_{\mathrm{e}}$ is nearly universal for post-flame smoke produced from over-ventilated combustion.

We have estimated a mean value of $\sigma_{\mathrm{e}}$ for all fuels of $9.25 \mathrm{~m}^{2} / \mathrm{g} \pm 1.17 \mathrm{~m}^{2} / \mathrm{g}$ at $632 \mathrm{~nm}$ and $5.40 \mathrm{~m}^{2} / \mathrm{g} \pm$ $0.57 \mathrm{~m}^{2} / \mathrm{g}$ at $1064 \mathrm{~nm}$. These results are in good agreement with values reported by Mulholland \& Croarkin [1] and Newman \& Steciak [2] of $8.7 \mathrm{~m}^{2} / \mathrm{g} \pm 1.1 \mathrm{~m}^{2} / \mathrm{g}$ at $633 \mathrm{~nm}$ and $5.6 \mathrm{~m}^{2} / \mathrm{g} \pm 0.69 \mathrm{~m}^{2} / \mathrm{g}$ at $1060 \mathrm{~nm}$. Recently, Schnaiter et al [12] have found $7 \mathrm{~m}^{2} / \mathrm{g}$ and $5 \mathrm{~m}^{2} / \mathrm{g}$ respectively at 632 and $1064 \mathrm{~nm}$ for diesel soot. This is less than the previous results, and this can be explained by the formation process which are very different in a diesel engine and in over-ventilated flames produced at atmospheric pressure.

These mean values of mass specific extinction coefficient are very useful in order to determine the mass concentration of soot particles with only extinction coefficient measurements in smokes and fires. However further investigations need to be done to look at the influence of soot temperature on $\sigma_{\mathrm{e}}$, since the soot samples were at ambient temperature in the present work. 


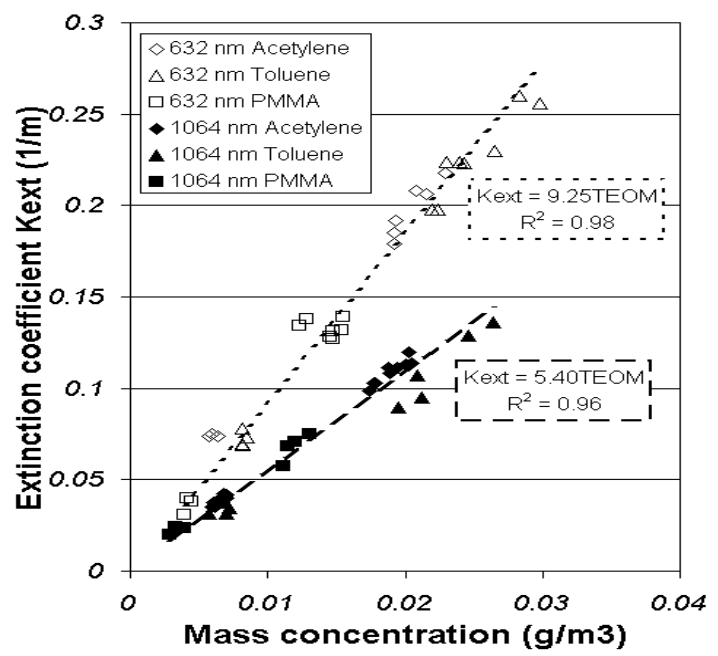

Fig. 4. Comparison of extinction coefficients with TEOM mass concentrations of soot particles

\section{Soot volume fraction}

The soot volume fraction can be calculated from the particle diameter distribution $f\left(D_{m b}\right)$

$$
f_{v c}=\sum_{D_{m b}} V_{a g g}\left(k_{f}, D_{f}, D_{p p}^{f}, D_{m b}, \beta\right) f\left(D_{m b}\right)
$$

where $\mathrm{V}_{\text {agg }}$ is the volume of one aggregate calculated using the relation 3 and knowing the morphological parameter $k_{f}, D_{f}$ and $D_{p p}$. The SMPS range is limited to particles with a mobility diameter below $850 \mathrm{~nm}$, so the size distribution $\mathrm{f}\left(\mathrm{D}_{\mathrm{mb}}\right)$ was fitted with a log-normal function and extended up to $2000 \mathrm{~nm}$.

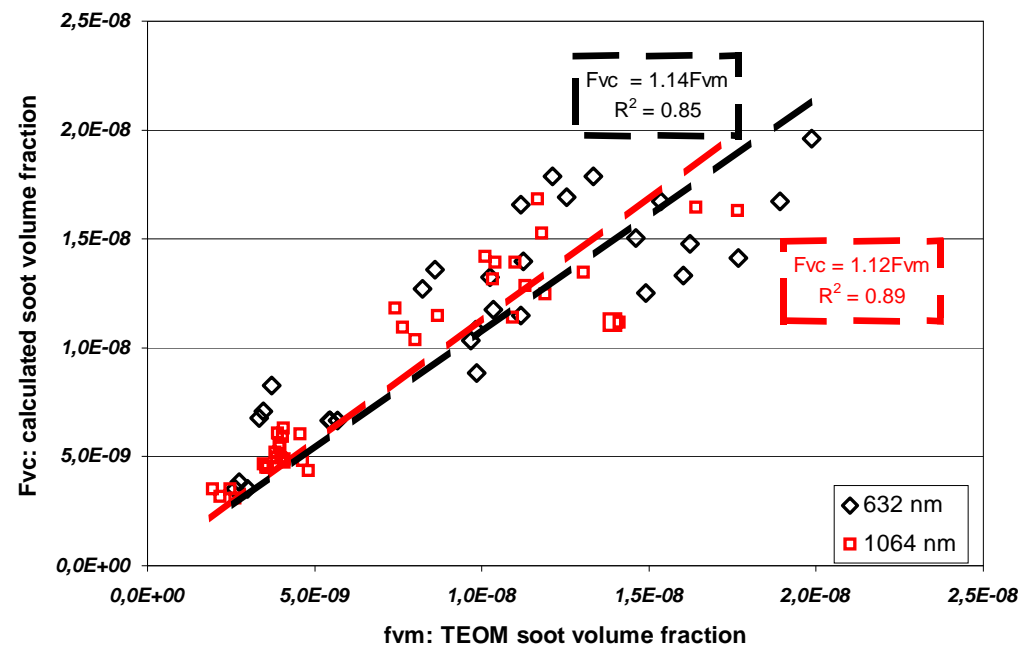

Fig. 5. Comparison of calculated soot volume fraction with measured values obtained using a TEOM.

The $\mathrm{f}_{\mathrm{vc}}$ values are calculated with soot particle properties given in table 2, and for all experimental points. The calculated soot volume fraction $\mathrm{f}_{\mathrm{vc}}$ are compared in Fig. 5 to the values determined from TEOM observations, $\mathrm{f}_{\mathrm{vm}}=\mathrm{C}_{\mathrm{s}} / \rho_{\mathrm{pp}}$. The soot density $\rho_{\mathrm{pp}}$ reported in Table 2 has been used to convert TEOM mass concentration $\mathrm{C}_{\mathrm{s}}$ into soot volume fraction $\mathrm{f}_{\mathrm{vm}}$. 
The main conclusion is that the two volume fractions are well correlated. The slopes of the linear curves at the two wavelengths are close to one indicating a rather good agreement. The small discrepancy is about $10 \%$. This good consistency underlines the reliability of our method for determining soot volume fractions from simultaneously measurements of the agglomerate size distribution and morphological parameters.

\section{Dimensionless soot extinction coefficient $K_{e}$}

Soot particle volume fraction fv can be also determined using the light extinction technique. It consists in measuring the ratio of the transmitted to the incident light intensity in order to obtain the soot volume fraction $f v$, which is possible if the dimensionless soot extinction $\mathrm{K}_{\mathrm{e}}$ is known, as shown in relation 2.

$\mathrm{K}_{\mathrm{e}}$ is composed of absorption and scattering parts $[3,13]$. With the present results, they could be computed with the RDG-FA approximation, knowing the mobility diameter distribution $\mathrm{f}\left(\mathrm{D}_{\mathrm{mb}}\right)$ and the morphological parameters of soot particles

$$
K_{\text {ext }}=\overbrace{C_{a} E(m) \sum_{D_{m}} D_{m b}^{d_{f}} f\left(D_{m b}\right)}^{K_{\text {abs }}}+\overbrace{C_{b} F(m) \sum_{D_{m}} D_{m b}^{2 d_{f}} g\left(\lambda, D_{m}\right) f\left(D_{m b}\right)}^{K_{\text {sca }}}
$$

with constants $\mathrm{C}_{\mathrm{a}}$ and $\mathrm{C}_{\mathrm{b}}$ given by

$$
C_{a}=\frac{\pi^{2} \beta^{d_{f}} k_{f} D_{p}^{3-d_{f}}}{\lambda} C_{b}=\frac{2 \pi^{5} \beta^{2 d_{f}} k_{f}^{2} D_{p}^{6-2 d_{f}}}{3 \lambda^{4}}
$$

In these relations, $g$ is a form factor, $\mathrm{E}(\mathrm{m})$ and $\mathrm{F}(\mathrm{m})$ are well known functions of the complex refractive index of soot $[6,13,14]$, the other parameters have been already defined. The RDG-FA theory has been introduced by Köylü and Faeth $[6,13]$ and its validity has been checked by comparison with more accurate formulations $[15,16]$. However the main difficulty of the application of the above relations is that the complex refractive index $\mathrm{m}$ value of soot particles has to be known. Up to now, this value is not determined with accuracy.

In this study, the dimensionless soot extinction coefficient $K_{e}$ is determined directly from $K_{\text {ext }}$ measurements and previous calculated $\mathrm{f}_{\mathrm{vc}}$ values. As shown in Fig.4, $\mathrm{K}_{\mathrm{ext}}$ is not strongly influenced by the fuel nature for the present conditions. So an unique Ke value is determined and the average has been worked out for all points given in Fig.5 and at the two wavelengths, and they are reported in table 3 with recent data obtained by Zhu $[3,4]$ for comparison.

Table 3. Dimensionless soot extinction coefficient $K_{e}$ obtained in this work and previous studies [3,4]. The uncertainties correspond to the estimated $95 \%$ confidence level.

\begin{tabular}{|c|c|c|c|c|}
\hline $\begin{array}{c}\text { Wavelength } \\
(\mathrm{nm})\end{array}$ & $\begin{array}{c}\text { JP-8 Ke } \\
{[4]}\end{array}$ & $\begin{array}{c}\text { Ethene Ke } \\
{[3]}\end{array}$ & $\begin{array}{c}\text { Acetylene Ke } \\
{[3]}\end{array}$ & $\begin{array}{l}\text { Acetylene, Toluene } \\
\text { and PMMA } \\
\text { mean value } \\
\text { Present work }\end{array}$ \\
\hline 632.8 & 9.87 & $9.65+/-0.40$ & $8.12+/-0.44$ & $7.77+/-0.48$ \\
\hline 856 & 9.95 & $9.35+/-0.38$ & $8.83+/-0.52$ & \\
\hline 1064 & & & 8.96 (interpolated) & $7.94+/-0.36$ \\
\hline 1314 & 9.75 & $9.17+/-0.46$ & $9.12+/-0.62$ & \\
\hline 1565 & 9.76 & $9.19+/-0.48$ & $10.0+/-0.80$ & \\
\hline
\end{tabular}


For acetylene and at $632 \mathrm{~nm}$, the present value is in agreement with the Xhu's one, therefore at 1064nm, this is not true since Xhu's interpolated value is larger than the present one. For JP-8 and ethene, the differences are much greater than the differences observed for acetylene.

It is shown in table 3 that Ke seems to be not very wavelength dependent for the experimental conditions encountered in this work. From relations 1 and 2, it is found $\sigma_{\mathrm{e}}=\mathrm{K}_{\mathrm{e}} /\left(\rho_{\mathrm{s}} \lambda\right)$, this indicate that $\sigma_{\mathrm{e}}$ is supposed to be inversely proportional to the wavelength $\lambda$. This is experimentally confirmed by the ratio between values $\sigma_{\mathrm{e}}(632)$ and $\sigma_{\mathrm{e}}(1064)$ which is $9.25 / 5.4$ and is nearly equal to the wavelengths ratio $1064 / 632$.

The wavelenght dependence of $\mathrm{Ke}$ is explained by both the wavelength influence on $\mathrm{K}_{\mathrm{abs}}$ and $\mathrm{K}_{\text {sca }}$, and without information on the refractive index value, it is not possible to conclude which process, absorption or scattering, is the most wavelength dependent. Analysis of relation 5 helps to understand the influence of the soot aggregate properties and wavelength on Ke. Relation 5 can be rewritten and expressed in terms of soot volume fraction

$$
K_{\text {ext }}=\overbrace{6 \Pi E(m) f v / \lambda}^{K_{a b s}}+\overbrace{C_{b} F(m) \sum_{D_{m}} D_{m b}^{2 d_{f}} g\left(\lambda, D_{m b}\right) f\left(D_{m b}\right)}^{K_{s c a}}
$$

We can see that the $\mathrm{K}_{\text {ext }}$ wavelength dependence is due to the two terms: $\mathrm{E}(\mathrm{m}) / \lambda$ in $\mathrm{K}_{\mathrm{abs}}$ and $\mathrm{F}(\mathrm{m}) * \mathrm{~g}\left(\lambda, \mathrm{D}_{\mathrm{mb}}\right) / \lambda^{4}$ in $\mathrm{K}_{\text {sca }}$.

First of all, it is interesting to estimate the contribution of scattering to the extinction process. This contribution is defined by the ratio $\rho_{\text {sca }}=\mathrm{K}_{\text {sca }} / \mathrm{K}_{\text {ext }}$. The values have been obtained with the RDG-FA theory, knowing the measured soot particle size distribution and morphology and using available refractive index values. At $632 \mathrm{~nm}$, the most popular data, namely Lee-Tien's [17] and Dalzell-Sarofim's [18] values, are respectivelly $\mathrm{m}_{\mathrm{LT}}=1.84-0.47 \mathrm{i}$ and $\mathrm{m}_{\mathrm{D}}=1,56-0,46 . \mathrm{i}$, the last one being an average value from $436 \mathrm{~nm}$ to $806 \mathrm{~nm}$. The $\rho_{\text {sca }}$ results show a contribution equal to nearly $45 \%$ and $56 \%$ for respectively Lee-Tien's and Dalzell-Sarofim's value. Recently, Krishnan et al. [19] reported a refractive index of $\mathrm{m}_{\mathrm{K}}=1.99-0.89 . \mathrm{i}$ at the same wavelength for soot at standard temperature in the overfire region of flames. This gives a lower value of $\rho_{\text {sca }}$ equal to $32 \%$. These three estimations are rather different. Experimental determination of $\mathrm{K}_{\text {sca }}$ is not easy. Differential cross section variation with scattering angle has been performed by Weinert et al [20] for various non-flaming and flaming fire generated smoke aerosols. An angular truncated mass scattering cross section of acetylene $1.6 \mathrm{~m}^{\wedge} 2 / \mathrm{g}$ can be obtained, corresponding to $\rho_{\mathrm{sca}}=17 \%$. Total scattering $\left(\mathrm{K}_{\text {sca }}\right)$ value has been measured by Mulholland and Choi [21] using a reciprocal nephelometer. They found $\rho_{\text {sca }}$ equal to $22 \%$ and $25 \%$ respectively in laminar and turbulent acetylene flames. These values are lower than the ones previously calculated. This may be due to the low value of the imaginary part of the refractive indexes which have been chosen for the calculations. This is shown by the use of Krisnan's value 0.89 instead of Lee-Tien's or Dalzell-Sarofim's values which decreases the calculated $\rho_{\text {sca }}$ value. However all these results highlight the scattering is not negligible for the soot particles generated in the present study.

The $\rho_{\text {sca }}$ parameter is expected to decrease with longer wavelengths. At 1064, a few values of refractive index are available, therefore Krishnan [22] gives a $\mathrm{F}(\mathrm{m})$ value equal to 0.6524 , which values the albedo $\rho_{\text {sca }}$ at $17 \%$.

In conclusion, the scattering process is important for the present experimental conditions. This is mainly due to the primary particle diameters Dpp which are large (as shown in table 2). Much lesser values of the albedo have been observed by Schnaiter.[12] on diesel soot but with lesser particle diameter Dpp (27nm).

So, it is a crude approximation to neglect soot scattering in the relation 5 . The consequence is that the approach which is widely used and interprets light extinction measurements with relation 5 assuming $\mathrm{Kext}=6 \pi \mathrm{E}(\mathrm{m}) \mathrm{f}_{\mathrm{v}} / \lambda$, leads to an overestimate of soot volume fraction. For this reason, the use of the dimensionless coefficient is expected to provide a more accurate soot volume fraction value. The relation ship between fv and Kext is not obvious as seen in relation 5 and the exact meaning of Ke is not clear. However its definition does not assume the scattering can be neglected. 
As shown by relation 7, the $\mathrm{K}_{\mathrm{ext}}$ wavelength dependence appears both in $\mathrm{K}_{\mathrm{abs}}$ and $\mathrm{K}_{\mathrm{sca}}$. Without information on the refractive index values, it is not possible to give the exact relation between the wavelength and $K_{a b s}$ or $\mathrm{K}_{\text {sca. }}$. However, it has been found that $\sigma_{\mathrm{e}}$ is inversely proportional to the wavelength $\lambda$. This indicates that the sum $K_{\text {abs }}+K_{\text {sca }}$ must be inversely proportional to $\lambda$.

\section{CONCLUSIONS}

(1) A method has been developed in order to determine the mass specific extinction coefficient at 632 and $1064 \mathrm{~nm}$, and the soot particle volume fraction. It combines measurements of the extinction coefficients, agglomerate size distributions and morphological parameters .

(2) the mass specific extinction coefficient $\sigma_{\mathrm{e}}$ has been determined in the smokes of over-ventilated flames of acetylene, toluene and PMMA. $\sigma_{\mathrm{e}}$ is not sensitive to fuel type at both wavelengths. The present values have been found equal to $9.3 \mathrm{~g} / \mathrm{m}^{2}$ at $632 \mathrm{~nm}$ and $5.4 \mathrm{~g} / \mathrm{m}^{2}$ at $1064 \mathrm{~nm}$ and they are in agreement with previous results.

(3) Calculations of the soot volume fraction from agglomerate size distributions and morphological parameters are un agreement with values determined from soot mass concentrations Cs measured with a TEOM and using soot density $\rho_{\mathrm{s}}=1.72 \mathrm{Kg} / \mathrm{m}^{3}$ for acetylene and $1.5 \mathrm{Kg} / \mathrm{m}^{3}$ for toluene and PMMA.

(4) The dimensionless extinction coefficient $\mathrm{Ke}$ is found equal to 7.77 at $632 \mathrm{~nm}$ and 7.94 at $1064 \mathrm{~nm}$.

(5) At $632 \mathrm{~nm}$ and for the present experimental conditions, the contribution of the scattering to the extinction process cannot be neglected.

(6) Neglecting the scattering in the interpretation of the extinction coefficient at $632 \mathrm{~nm}$ may give an overestimation of the soot volume. The scattering intensity at longer wavelengths being lesser, it is recommended to performed such soot volume fraction determinations, which assumes negligible scattering, in the infrared.

\section{REFERENCES}

[1] Mulholland G W and Croarkin C (2000) Specific extinction coefficient of flame generated smoke Fire Mat. 24 227-230

[2] Newman J S and Steciak J (1987) Characterization of particulates from diffusion flames Combust. Flame 67 55-64, doi:10.1016/0010-2180(87)90013-7.

[3] Zhu J.Y. et al, (2002) Measurement of visible and near-ir optical properties of soot produced in laminar flames, Proceedings of the Combustion Institute, Volume 29, pp. 2367-2374, doi:10.1016/S1540-7489(02)80288-7.

[4] Zhu J.Y. et al, (2004) Measurement of light extinction constant of JP-8 soot in the visible and near-infrared spectrum, International Journal of Heat and Mass Transfer 47, 3643-3648, doi:10.1016/j.ijheatmasstransfer.2004.04.013.

[5] Ouf, F.X., Coppalle, A., Vendel, J., Weill, M.and Yon, J. (2008) Characterization of soot particles in the plume of over-ventilated diffusion flames, to appear in Comb. Sc; Techn.

[6] Köylü Ü Ö and Faeth G M 1993 Radiative properties of flame-generated soot J. Heat Transfer $115152-159$

[7] Köylü Ü Ö Faeth G M Farias T L and Carvalho M G 1995 Fractal and projected structure properties of soot aggregates Combust. Flame 100 621-633, doi:10.1016/0010-2180(94)00147-K.

[8] Sorensen C M and Feke G D 1996 The morphology of macroscopic soot Aerosol Sci. Technol. 25 328-337, doi:10.1080/02786829608965399.

[9] Köylü Ü Ö and Faeth G M 1991 Carbon monoxide and soot emissions from buoyant turbulent diffusion flames Symposium (International) on Fire Safety Science 3 625-634

[10] Tewarson A. 2002 Generation of heat and chemical compounds in fire in $3^{\text {rd }}$ Edition of the SFPE handbook of Fire Protection Engineering 
[11] Rogak S N and Flagan R C 1990 Stokes drag on self-similar clusters of spheres J. Colloid Interface Sci. 134 206-218, doi:10.1016/0021-9797(90)90268-S.

[12] Schnaiter M. , Horvath H., Mohler O, Naumann K.H., Saathoff H., Schock W.0., (2003) UV-VISNIR spectral optical properties of soot and soot-containing aerosols, Aerosol Science 34 14211444, doi:10.1016/S0021-8502(03)00361-6.

[13] Dobbins, R. A., Mulholland, G. W., and Bryner, N. P., (1994) Comparison of a fractal smoke optics model with light extinction measurements, Atmos. Environ. 28,889, doi:10.1016/13522310(94)90247-X.

[14] Bohren C F and Huffman D R 1983 Absorption and scattering of light by small particles

[15] Farias T L Köylü Ü Ö and Carvalho M G 1996 Range of validity of Rayleigh-Debye-Gans theory for optics of fractal aggergates Applied Optics 35 6560-6567

[16] Van Hulle P., Weill M., Talbaut M. and Coppalle A., (2002) Comparison of numerical studies characterizing optical properties of soot aggregates for improved EXSCA measurements. Part. Part. Syst. Charact. 19, 1-11, doi:10.1002/1521-4117(200204)19:1<47::AID-PPSC47>3.0.CO;2W.

[17] Lee S C and Tien C L 1981 Optical constant of soot in hydrocarbon flames Proc. Combust. Inst. 18 1159-1166

[18] Dalzell W H and Sarofim A L (1969) Optical constants of soot and their application to heat-flux calculations J. Heat Transfer 91 100-104

[19] Krishnan S S, Lin K -C and Faeth G M (2000) Optical properties in the visible of overfire soot in large buoyant turbulent diffusion flames ASME J. Heat Transfer 122 517-524, doi:10.1115/1.1288025.

[20] Weinert D.W., Cleary T.G., Mulholland G.W. and Beever P.F (2002) Light scattering characteristics and size distribution of smoke and nuisance aerosols, Symposium (International) on Fire Safety Science 7 209-220

[21] Mulholland G.W. and Choi M.Y. (1998) Measurement of the mass specific extinction coefficient for acethylene and ethane using the large agglomerate optics facility, Proceedings of the Combustion Institute, Volume 27, pp. 1515-1522

[22] Krishan S S, Faeth G M, Lin K -C (2001) Extinction and scattering properties of soot emitted from buoyant turbulent diffusion flames J. Heat Transfer 123 331-339, doi:10.1115/1.1350823. 